\title{
ELE NÃO QUERIA APENAS FAZER PARTE DE UM MOVIMENTO JUVENIL. UMA INTERPRETAÇÃO DO DIREITO LIVRE DE HERMANN KANTOROWICZ.'
}

\author{
HE DIDN'T JUST WANT TO BE PART OF A YOUTH MOVEMENT. \\ AN INTERPRETATION OF HERMANN KANTOROWICZ'S FREE LAW.
}

\begin{abstract}
Andreas Funke
Professor Catedrático de Direito Público e Filosofia do Direito na Friedrich-AlexanderUniversität - Erlangen-Nuremberg, Alemanha.
\end{abstract}

\begin{abstract}
Resumo
Para Hermann Kantorowicz (1877-1940), a filosofia jurídica era parte natural de sua impressionante formação jurídica acadêmica. No entanto, seu trabalho sobre filosofia jurídica é fragmentário e precisa ser reconstruído. Fazendo isso, o conceito "clássico" de direito livre de Kantorowicz aparece sob uma nova luz. Ele sempre teve dificuldades em afirmar exatamente o que realmente é o direito livre. Nos últimos trabalhos de Kantorowicz, o conceito de dogmas assume a posição que ocupava o direito livre nos primeiros trabalhos. Dogmas e direito livre são funcionalmente equivalentes. O direito não é simplesmente comandos, ou seja, ordens ou normas autorizativas, ou seja, declarações que são percebidas como obrigatórias. O direito é acima de tudo dogma, isto é, um corpo de entidades significativas atuando por meio de uma lógica específica de acomodação coerente. O conceito de dogma supera, portanto, a oposição tradicional entre reconhecer e inventar o direito. Kantorowicz enfatiza como a ciência jurídica e os tribunais também são, em certo sentido, parte do direito, apenas argumentando razoavelmente de maneira jurídica.
\end{abstract}

Palavras-chave: Direito livre; Kantorowicz; Dogmática jurídica; Conceito de Direito; Raciocínio jurídico.

\begin{abstract}
For Hermann Kantorowicz (1877-1940), legal philosophy was a natural part of his impressively broad academic legal education. Yet his work on legal philosophy is fragmentary and needs reconstruction. Doing this, Kantorowicz's "classic" concept of free law
\end{abstract}

\footnotetext{
${ }^{1}$ Tradução de Marcos Augusto Maliska do original em alemão publicado em Ino Augsberg/Saskia Lettmaier/Rudolf Meyer-Pritzl (Orgs.), Hermann Kantorowicz' Begriff des Rechts und der Rechtswissenschaft, Tübingen: Mohr Siebeck.
} 
appears in a new light. He has always had difficulties in stating exactly what the free law actually is. In Kantorowicz's late work, the concept of dogmas takes on the position that occupied free law in the early works. Dogmas and free law are functionally equivalent. The law is not simply the commands, i.e., authoritative orders, or norms, that is, statements that are perceived as mandatory. The law is above all dogma, that is, it is a body of meaningful entities processing via a specific logic of coherent accommodation. The concept of dogma therefore overcomes the traditional opposition of recognizing and inventing the law. Kantorowicz emphasizes how legal science, and the courts as well, are in a certain sense part of the law, solely by arguing reasonably in the legal mode.

Keywords: Free law; Kantorowicz; Legal doctrine; Concept of law; Legal reasoning.

\section{A. Como podem ser lidos os fragmentos jurídico-filosóficos de Kantorowicz?}

Para Kantorowicz, a filosofia do direito era uma parte evidente de sua impressionante formação jurídica acadêmica. Ele ofereceu regularmente cursos de filosofia do direito, revisou e escreveu ensaios. Mas a filosofia do direito também era um projeto acadêmico: Kantorowicz planejou uma "filosofia do direito" fechada, tendo relatado isso em cartas $^{2}$ e anunciado em publicações. ${ }^{3}$ O livro não foi concluído. Qualquer pessoa que se aproxime do trabalho de Kantorowicz com interesse na filosofia do direito deve, portanto, se contentar com as publicações frequentemente incompletas e relacionadas à ocasião. Meu primeiro interesse em Kantorowicz, para começar com uma observação pessoal, chegou a lugar nenhum: em minha dissertação, sob o título de "Teoria Geral do Direito", lidei com a teoria jurídica alemã do início do século XX e tentei extrair um campo de pesquisa da complexa discussão da época que buscou desenvolver uma teoria jurídica analítica estruturante.

\footnotetext{
2 Em suas cartas a Gustav Radbruch, Kantorowicz menciona ocasionalmente o trabalho sobre uma "filosofia jurídica". Quando foi declarado capaz de servir em campo durante a guerra, ele organizou o manuscrito "por precaução" para que sua esposa pudesse publicá-lo (carta de 26 de maio de 1916, Konvolut Universitätsarchiv Freiburg, Caderno 161). Em 25 de janeiro de 1918, ele escreveu: "Eu trabalho todos os dias em minha filosofia jurídica, que se transforma em, e ganha corpo como, um ser vivo" (Konvolut Universitätsarchiv Freiburg, Caderno 174). Na carta de 21 de maio de 1918 (mesmo Caderno), ele relata outros trabalhos sobre o assunto.

${ }^{3}$ Karlheinz Muscheler, Relativismus und Freirecht. Ein Versuch über Hermann Kantorowicz, Heidelberg 1984, p. 38.
} 
Kantorowicz foi uma figura marginal para este projeto. ${ }^{4}$ Ele não estava tematicamente envolvido no projeto, e o trabalho que ele havia escrito no campo da pesquisa mostrou-se pouco útil. Os escritos de Kantorowicz sobre direito livre eram levemente polêmicos, mas sistematicamente insatisfatórios em seu voluntarismo bastante simples. ${ }^{5}$ As críticas à "Doutrina do Direito Correto" de Rudolf Stammler eram afiadas, precisas e convincentes - mas, como crítica, especialmente por causa de uma frágil filosofia do direito, os escritos careciam da perspectiva construtiva. ${ }^{6}$ Os textos de Kantorowicz sobre sociologia jurídica eram elegantes e delineavam um interligado sistema científico. ${ }^{7}$ É claro, eles acrescentaram apenas algumas nuances aos projetos neokantianos de Max Weber, Heinrich Rickerts ou Emil Lasks, o que me pareceu ter algum valor, acima de tudo, para a própria sociologia jurídica.

Como o trabalho jurídico-filosófico de Kantorowicz é fragmentado, as características básicas de sua visão jurídico-filosófica devem ser reconstruídas a partir dos escritos mencionados. Trabalhos de outras áreas, como os de direito penal dogmático, são úteis. De fato, nem sequer é possível determinar os valores de referência de um campo a ser preenchido. Isso é diferente, por exemplo, na "filosofia do direito" de seu amigo Gustav Radbruch, que revela uma certa estrutura sistemática de fora: $\S 1$ realidade e valor, $\S 2$ filosofia do direito como consideração valorativa do direito e assim por diante. ${ }^{8}$ Interpretar um autor como Radbruch é, portanto, a meu ver, diferente de interpretar Kantorowicz. Em Kantorowicz, os intérpretes são muito mais dependentes de uma abordagem extrapoladora. ${ }^{9}$ Inevitavelmente, a liberdade para trabalhar os textos é maior. As reflexões do presente texto fazem uso cuidadoso dessa liberdade. Antes de tudo, deve ser explicado em que sentido uma reconstrução dos fragmentos da filosofia do direito de Kantorowicz parece promissora (item B).

\footnotetext{
${ }^{4}$ Embora ele sempre tivesse um olho benevolente na teoria jurídica geral e lhe desse um lugar na teoria jurídica, veja, por exemplo, Hermann Kantorowicz, Der Begriff des Rechts, Göttingen [1963], p. 37 s. Um pouco mais cético, no entanto, a Resenha de: Adolf Reinach, Die apriorischen Grundlagen des bürgerlichen Rechts, Logos 8 (1919), p. 111 (112).

${ }^{5}$ Hermann Kantorowicz, Der Kampf um die Rechtswissenschaft (1906), in: id. Rechtswissenschaft und Soziologie, Thomas Würtenberger (Org.), Karlsruhe 1962, p. 1.

${ }^{6}$ Hermann Kantorowicz, Zur Lehre vom richtigen Recht, Berlin Leipzig 1909.

7 Hermann Kantorowicz, Rechtswissenschaft und Soziologie (1911), in: id. Rechtswissenschaft (N.R. 4), p. 117.

${ }^{8}$ Gustav Radbruch, Rechtsphilosophie, 3a ed., 1932 (Reimpressão Heidelberg 1999).

${ }^{9}$ Muscheler, em Relativismus und Freirecht, enfatiza a necessidade de extrapolação, repetidas vezes em seu trabalho fundamental sobre Kantorowicz; sobre o caráter fragmentário Ino Augsberg, Hermann Kantorowicz und die Freiheit des Rechts, in: Andreas von Arnauld/Ino Augsberg/Rudolf Meyer-Pritzl (Orgs.), 350 Jahre Rechtswissenschaftliche Fakultät der Christian-Albrechts-Universität zu Kiel, Tübingen 2018, p. $191(195,215)$.
} 
Kantorowicz atribuiu grande importância ao esclarecimento conceitual, epistemológico e ontológico do conceito de "direito". Em seu trabalho tardio, isso evidentemente o levou de volta ao direito livre (item $\mathrm{C}$ ). O direito livre é entendido, principalmente na literatura secundária, como uma figura metodológica para preencher as lacunas do direito, e o próprio Kantorowicz o expôs dessa maneira. ${ }^{10}$ No entanto, a uma certa distância das interpretações anteriores, penso que o direito livre se refere realmente ao tratamento dogmático do direito e, portanto, a um procedimento que - ao contrário do termo - é tudo menos livre, mas envolve uma variedade de laços. Isso é para preservar nada menos que a razoabilidade do direito (item D).

\section{B. Objetivos e normas}

Atualmente, dificilmente se discute que o sistema jurídico "não deve ser visto apenas como ordens individuais [...], mas como um todo que é razoavelmente ordenado por meio de propósitos e intenções gerais". ${ }^{11}$ No entanto, demorou muito tempo para a teoria jurídica analítica de língua alemã chegar a essa conclusão. A esse respeito, a teoria jurídica poderia ter se inspirado na "Finalidade do Direito" de Rudolf von Jhering, de 1877 e 1884, no último terço do século XIX. Mas ela era - na forma da já mencionada teoria jurídica geral - o Jhering antes do "momento decisivo", que em seu "método de história natural" estava na trilha do "alfabeto do direito", entendido como "um direito reduzido a seus momentos lógicos". ${ }^{12}$ No contexto da teoria jurídica analítica, foi apenas Ronald Dworkin, em suas críticas a H. L. A. Hart, que tentou mostrar que o direito contém mais do que apenas ordens individuais, mas também fundamentos e princípios jurídicos. ${ }^{13}$ Com a constatação generalizada, também feita

\footnotetext{
10 Veja, por exemplo, Monika Frommel, Hermann Ulrich Kantorowicz (1877-1940), in: Helmut Heinrichs/Harald Franzki entre outros (Orgs.), Deutsche Juristen jüdischer Herkunft, München 1993, p. 631 (636) Uma definição interessante do direito livre não está disponível; Kantorowicz faz uma apresentação comparativamente curta, mas ainda em meia página, das ideias básicas do direito livre em Hermann Kantorowicz, Rationalistische Bemerkungen über Realismus (1934), in: id., Rechtswissenschaft (N.R. 4), p. 101 (102).

11 Ota Weinberger, Norm und Institution. Eine Einführung in die Theorie des Rechts, Wien 1988, p. 96.

12 Rudolf von Jhering, Geist des römischen Rechts auf den verschiedenen Stufen seiner Entwicklung, Primeira Parte, 9a ed., Darmstadt 1953, p. 41. Ver também Christoph-Eric Mecke, Begriff des Rechts und Methode der Rechtswissenschaft bei Rudolf von Jhering, Göttingen 2018, p. 472 s.; Andreas Funke, Allgemeine Rechtslehre als juristische Strukturtheorie. Entwicklung und gegenwärtige Bedeutung der Rechtstheorie um 1900, Tübingen 2004, p. 103 s.; sobre o „Ponto de Virada“ Mecke, Begriff des Rechts, p. 242 s., p. 345 s.; Okko Behrends, Jherings „Umschwung“, Zeitschrift der Savigny-Stiftung für Rechtsgeschichte, Romanistische Abteilung 134 (2017), p. 539.

${ }^{13}$ Ronald Dworkin, Taking Rights Seriously, Cambridge 1977, p. 14 s.
} 
por Kantorowicz, de que, com Jhering, uma nova Era, orientada pela finalidade ${ }^{14}$, havia começado na ciência do direito alemã, as coisas não ficaram muito claras. E, por último, mas não menos importante, o próprio Kantorowicz foi um ator importante naquela época por meio do, assim por ele chamado, movimento do direito livre.

No entanto, não está muito claro, qual significado jurídico tem os objetivos. As dificuldades podem ser ilustradas usando a teoria de Dworkin que acabamos de mencionar. A distinção entre regras e princípios foi expandida na Alemanha para formar a base de uma verdadeira teoria universal do direito. ${ }^{15} \mathrm{O}$ próprio Dworkin mais tarde a negligenciou em favor de um conceito mais hermenêutico. Ele vê o direito como uma prática social que, em certo sentido, se interpreta, e essa prática é caracterizada pelo fato de estar essencialmente preocupada com fins e não com causas. ${ }^{16}$ Esses não são os objetivos que qualquer autor está perseguindo, mas aqueles que o intérprete constrói como parte de uma interpretação construtiva. É atribuir um objetivo a um objeto ou prática, a fim de tornar o objeto o melhor exemplar possível da forma ou gênero ao qual o objeto pertence. ${ }^{17}$ Dworkin chama isso de atitude interpretativa. ${ }^{18}$ No direito isso significa que os juízes, por exemplo, formam teorias sobre qual ponto, ou seja, qual finalidade justificável está subjacente ao respectivo sistema jurídico como um todo. ${ }^{19} \mathrm{Em}$ última análise, portanto, os juízes se esforçam para encontrar um equilíbrio entre a prática jurídica encontrada e a melhor justificativa possível para essa prática. ${ }^{20}$

Penso que é uma pergunta muito interessante, qual o papel do conceito de finalidade em uma teoria jurídica hermenêutica pós-analítica e como ela se relaciona com o conceito de valor. Isso também pode ser especulado por um longo tempo com Gustav Radbruch, mas eu fico com Dworkin: que uma prática serve a uma finalidade

\footnotetext{
${ }^{14}$ Ver Hermann Kantorowicz, Die Epochen der Rechtswissenschaft (1914), in: Hermann Kantorowicz, Rechtshistorische Schriften, Karlsruhe 1970, S. 1 (13 f.). Para a importância de Jhering, incluindo diferenciações mais recentes, veja apenas Thomas Wischmeyer, Zwecke im Recht des Verfassungsstaates. Geschichte und Theorie einer juristischen Denkfiguar, Tübingen 2015, p. 55 s.; em Kantorowicz, p. 160 s. Kantorowicz enfatizou, ocasionalmente, a importância do Jhering tardio para o conceito de direito livre, ver Hermann Kantorowicz, Aus der Vorgeschichte der Freirechtsschule, Mannheim Berlin Leipzig 1925, p. 39; id., Tat und Schuld, Zürich Leipzig 1933, p. 25.

${ }^{15}$ Robert Alexy, Theorie der Grundrechte, 3a ed., Frankfurt am Main 1996.

16 Ronald Dworkin, Law's Empire, Cambridge, Mass. 1986, p. 51; ver. sobre as mudanças metodológicas Ken Kress, The Interpretive Turn, Ethics 97 (1987), p. 834.

17 Dworkin, Law's Empire, p. 52. Por conseguinte, a interpretação construtiva não visa identificar intenções históricas, mas o conceito de intenção fornece a estrutura formal para reivindicações interpretativas, Dworkin, Law's Empire, p. página 58. Também em D II.

18 Dworkin, Law's Empire, p. $46 \mathrm{~s}$.

19 Dworkin, Law's Empire, p. 87 s.

20 Dworkin, Law's Empire, p. 90 s.
} 
específica e que o intérprete atribui essa finalidade à prática, devendo, em sua teoria, ser sinônimo da atribuição, que o respectivo valor da prática tem, que serve a um certo interesse ou realiza um certo princípio. ${ }^{21}$ Mas os valores possuem validade e as finalidades, ao contrário, são definidas - essa diferença não deve mais desempenhar algum papel? Outro aspecto complica o problema. Para justificar os princípios morais e legais, Dworkin desenvolve um programa de justificação deontológico, influenciado por Kant, que julga as ações de acordo com as máximas nas quais elas se baseiam. ${ }^{22}$ Mas surge a questão da relação entre a visão teleológica, que faz parte da interpretação construtiva, e os procedimentos de justificação deontológica. É razoável supor que eles estão entrelaçados, mas é difícil dizer exatamente como isso deve ser.

Como tal, esta questão não pode ser examinada em mais detalhes nesse texto. Eu os levanto porque Hermann Kantorowicz observa uma justaposição similar de processos teleológicos e deontológicos. Duvido que seus escritos sejam produtivos o suficiente para responder à questão da relação entre esses dois processos. Mas se levarmos essa questão aos escritos de Kantorowicz, poderemos entender melhor a sua contribuição talvez mais efetiva à ciência do direito, a ideia de um direito livre.

\section{O conceito de direito na obra de Kantorowicz}

Típico para a sua época, Kantorowicz aborda o direito por meio do conceito de direito. Esse traço pode ser seguido mais de perto, porque Kantorowicz está lentamente desenvolvendo uma consistente compreensão em várias e bem diferentes tentativas.

\section{Definição nominal e real}

O ponto de partida no trabalho de Kantorowicz é a maneira pela qual Rudolf Stammler determinou o papel do conceito jurídico. Como um mantra, Stammler repetiu um argumento em seus escritos que Kantorowicz adotou e rejeitou de uma maneira

\footnotetext{
${ }^{21}$ Ver, talvez, Dworkin, Law's Empire, p. 47.

22 Ronald Dworkin, Justice for Hedgehogs, Cambridge, Massachusetts. 2011. Para Kant, o objetivo perseguido pelas pessoas com ações é "questão de arbitrariedade" e, como tal, é irrelevante para a determinação formal do conceito jurídico, Immanuel Kant, Metaphysik der Sitten, Primeira parte, in: Immanuel Kant, Werkausgabe, Vol. VIII, Wilhelm Weischedel (Org.), Frankfurt am Main 1977, p. 307, Einleitung in die Rechtslehre, § B.
} 
interessante. Stammler considerava que os termos jurídicos, o conceito de direito em si ou o conceito de direito correto, não podiam ser obtidos por meio da generalização de uma situação jurídica, porque era circular. Os conceitos teriam que ser estabelecidos previamente. ${ }^{23}$ Por causa desse argumento, a Stammler foi dado o mérito, por seus contemporâneos, de ter identificado claramente o problema epistemológico do direito. ${ }^{24}$ Consequentemente, autores como o próprio Stammler, Gustav Radbruch ou Julius Binder tiveram que supervalorizar, sob o ponto de vista transcendental-filosófico, o conceito de direito para contrariar o argumento circular. Kantorowicz não concorda com isso. Ele simplesmente aponta que é essencial estabelecer uma definição nominal ${ }^{25}$, pois ela permite que uma definição real seja desenvolvida, dependendo da contingência histórica do material jurídico. O único critério para a validação de uma definição nominal é sua produtividade científica. ${ }^{26} \mathrm{O}$ conhecimento começa com a definição real. ${ }^{27}$

É notável que Kantorowicz opte por um procedimento intermediário. Os neokantianos ficaram tontos com o que, segundo uma investigação, era "o círculo lógico do vórtice do qual nenhuma saída pode ser encontrada"28; alguns, como Felix Somló, se refugiaram na estranha ideia de um relativo a priori. ${ }^{29}$ Kantorowicz escapa habilmente do vórtice transcendental-filosófico, interpretando sua abordagem, considerando errada a questão das condições para a possibilidade de conhecimento jurídico. Kantorowicz parece-me rejeitar a afirmação de que a questão epistemológica de Kant pode ser significativamente aplicada à ciência do direito. ${ }^{30}$

Exatamente o mesmo procedimento definitivo, com uma terminologia ligeiramente diferente, pode também ser encontrado nas obras de Kantorowicz das décadas de 1920 e 1930, agora sob o lema "pragmatismo conceitual". ${ }^{31}$ Kantorowicz

\footnotetext{
${ }^{23}$ Ver, por exemplo, Rudolf Stammler, Theorie der Rechtswissenschaft, Halle/Saale 1911, p. 46 s.; mais evidências em Funke, Allgemeine Rechtslehre (N.R. 11), p. 157 s.

24 Julius Binder, Ueber kritische und metaphysische Rechtsphilosophie, ARWP 9 (1915/16), p. 142 (147).

${ }^{25}$ Hermann Kantorowicz, Zur Lehre vom richtigen Recht, p. 16 s.

26 Kantorowicz, Der Begriff des Rechts, p. 18

27 Ver Hermann Kantorowicz, Staatsauffassungen (1925), in: id., Rechtswissenschaft (N.R. 4), p. 69 (72).

${ }^{28}$ G. A. Wielikowski, Die Neukantianer in der Rechtsphilosophie, München 1914, p. 81.

${ }^{29}$ Felix Somló, Juristische Grundlehre, 2. Ed., Leipzig 1927, p. 127.

${ }^{30} \mathrm{O}$ que os neo-kantianos acabaram de tentar na filosofia do direito, ver Wielikowski, Die Neukantianer in der Rechtsphilosophie, p.. 10; Horst Dreier, Rechtslehre, Staatssoziologie und Demokratietheorie bei Hans Kelsen, 2a. ed., Baden-Baden 1990, p. 70; Wolfgang Kersting, Neukantianische Rechtsbegründung, in: id., Politik und Recht, Weilerswist 2000, p. 334 (338 s.).

${ }^{31}$ Kantorowicz, Staatsauffassungen, p. 73; id., Legal Science, Columbia Law Review 28 (1928), p. 679 (681); id., Der Begriff des Rechts, p. 22.
} 
aplica-o à necessidade de ordem, em um projeto de história jurídica global, no contexto de uma análise das "concepções de Estado" no conceito de Estado e, posteriormente, para o conceito de direito. A definição jurídica expressamente estabelecida neste contexto está oculta na abordagem abaixo, precisamente porque possui essas funções específicas. ${ }^{32}$ Em outras palavras, deve-se a uma perspectiva do observador sobre o direito. Kantorowicz assume a perspectiva do participante no contexto de sua teoria jurídica. Aqui ele desenvolve outra determinação do direito que merece nossa atenção.

\section{II - Direito como forma de significado}

Em seus estudos teóricos, Kantorowicz, a partir de 1919, atribui ao direito um lugar ontológico. Ele pretende, de maneira estrita, diferenciar realidade, significado e valor. Por trás dela, uma certa epistemologia, seu (famoso) "trialismo de métodos" (Methodentrialismus). ${ }^{33} \mathrm{O}$ direito deve ser entendido como uma forma de significado, como os números. ${ }^{34}$ Ao contrário dos números, o direito é temporal. Como estrutura de significado, o direito deve ser separado da realidade física e psicológica, ou seja, das ações naturais ou processos psíquicos, bem como dos valores. O significado e o valor do direito obviamente andam lado a lado nesse acesso. Isso é diferente de Radbruch, que busca uma conexão através do princípio da relação de valor teórico. De acordo com a conhecida frase sombria de Radbruch, o conceito de direito não pode ser determinado de nenhuma outra maneira que não a realidade, que tem o objetivo de servir à ideia jurídica. ${ }^{35}$ Kantorowicz começa algo diferente. Segundo Kantorowicz, como forma de significado o direito pode ser medido pelas ciências valorativas relevantes, a saber, a política jurídica e a filosofia jurídica, pelos valores.

\footnotetext{
32 Ver Kantorowicz, Begriff des Rechtes, p. 28; a definição, p. 36 s. No entanto, coincide com o termo estabelecido em Legal Science, id., Rechtswissenschaft - Eine kurze Zusammenfassung ihrer Methodologie (1928), in: id., Rechtswissenschaft, p. 89.

${ }^{33}$ Ver, pela primeira vez, em detalhes, provavelmente em Kantorowicz, Staatsauffassungen; mais adiante Legal Science, p. 682 s.; id. The Concept of the State, Economica [LSE] 12 (1932), S. 1 (2 ff.) ${ }^{34}$ Kantorowicz, Resenha de Adolf Reinach, Die apriorischen Grundlagen des bürgerlichen Rechts, $\mathrm{p}$. 115.

${ }^{35}$ Radbruch, Rechtsphilosophie, p. 3; para interpretação, ver apenas, na literatura mais recente, as diferentes posições em Andreas Funke, Radbruchs Rechtsbegriffe, ihr neukantianischer Hintergrund und ihr staatsrechtlicher Kontext, in: Martin Borowski/Stanley L. Paulson (Orgs.), Die Natur des Rechts bei Gustav Radbruch, Tübingen 2015, p. 23 (28 s.); Ulfrid Neumann, Zum Verhältnis von Rechtsgeltung und Rechtsbegriff, id., p. 129 (133 s.); Ralf Dreier, Kontinuitäten und Diskontinuitäten in der Rechtsphilosophie Radbruchs, id., p. 183 (195 s.).
} 
O pré-requisito para isso é que o significado seja determinado primeiro. ${ }^{36}$

"Investigamos o significado do direito objetivo quando colocamos a questão construtiva, a qual resulta de suas possíveis interpretações, juntamente com todos os outros preceitos jurídicos, em um todo consistente; seu valor, se fizermos a pergunta crítica, se esse sentido é apenas um [...] ".37

Segundo Kantorowicz, os valores se relacionam com a realidade. Eles devem ser realizados ou não devem ser realizados. ${ }^{38}$ Os valores são objetivamente válidos, isto é, sua validade não depende de nosso conhecimento e vontade. ${ }^{39}$ No entanto, os valores práticos da moralidade ou da justiça não são universais, mas apenas relativos. ${ }^{40}$ Kantorowicz atribui isso, entre outros, ao fato de que existem diferentes tipos de consciência em segundo plano, que divergem em diferentes tipos de objetivos finais. Os valores são identificados pela razão, ou seja, reconhecendo nosso dever de agir de uma certa maneira. ${ }^{41}$ Kantorowicz explica brevemente como isso se parece na prática: "As categorias de evidência são principalmente teleológicas, ou seja, meios e finalidades". ${ }^{42}$ Aqui vemos exatamente a justaposição de considerações teleológicas e deontológicas que mencionei anteriormente. Do relativismo de valor, a ciência segue o mandamento de se conter: julgamentos práticos de valor são negados à ciência, ela só pode ter juízos de valor como seu objeto, ordenação sistemática, etc. ${ }^{43}$

\section{A ciência do direito como ciência valorativa}

De acordo com o acima exposto, a ciência do direito seria uma ciência dos sentidos, por assim dizer. Ela não se julgaria. Mas, surpreendentemente, essa conclusão não pode ser tirada. A ciência jurídica ocupa um lugar especial na teoria da ciência de Kantorowicz. A rigor, ela está fora do esquema das disciplinas. ${ }^{44}$ Como Kantorowicz aponta - talvez em uma fase de transição para a sua obra tardia - ela não é ciência da palavra, mas ciência valorativa. ${ }^{45}$ Isso deve ser sinônimo do fato de

\footnotetext{
36 Ver Kantorowicz, Staatsauffassungen, p. 71 s.; Kantorowicz, Rechtswissenschaft, p. 87.

37 Kantorowicz, Staatsauffassungen, p. 72.

38 Kantorowicz, Staatsauffassungen, p. 86.

39 Kantorowicz, Staatsauffassungen, p. 86.

40 Kantorowicz, Staatsauffassungen, p. 86.

${ }^{41}$ Kantorowicz, Staatsauffassungen, p. 87; id. Begriff des Rechtes, p. 87.

42 Kantorowicz, Staatsauffassungen, p. 87.

43 Kantorowicz, Staatsauffassungen, p. 87.

${ }^{44}$ Kantorowicz, Rechtswissenschaft und Soziologie, p. 134.

45 Kantorowicz, Rechtswissenschaft und Soziologie, p. 126.
} 
que a ciência do direito "serve aos propósitos da vida social". Esses fins, como Kantorowicz ressalta, não são os que o "legislador" buscou, isto é, que seriam encontrados nos materiais. ${ }^{46}$ Antes, eles devem ser inferidos dos efeitos da lei. Os efeitos são aqueles que devem ser considerados valiosos no sentido da lei. O juiz teve que tratar os propósitos do sistema jurídico como "autoritativos e intocáveis", razão pela qual teve que determinar meios para esses objetivos, o que requer uma análise causal. ${ }^{47}$ Mas, além dessa visão causal, há uma visão avaliativa, porque os interesses perseguidos pela lei teriam que ser medidos em relação a um "valor cultural". Esse valor cultural nada mais é do que "a totalidade dos objetivos perseguidos por um determinado sistema jurídico". ${ }^{48}$ A questão deve ser, segundo Kantorowicz, se os efeitos sociais de uma norma justificariam seu estabelecimento hoje. ${ }^{49}$

Para a ciência do direito, isso significa que ela se avalia como "ciência normativa", como diz o próprio Kantorowicz.

\begin{abstract}
"Portanto, a sociologia do direito é uma ciência teórica que generaliza a realidade da vida social em relação ao valor cultural do objetivo do direito. A jurisprudência dogmática, por outro lado, se encontra fora desse esquema, pois, como podemos ver facilmente após superar a antiga teoria racionalista da ciência do direito, ela não se refere - teoricamente - a valores, mas se autoavalia - como ciência normativa - (nomeadamente sob procedimentos generalizados). Nos dois casos, não faz diferença se o jurista individualmente reconhece ou não o valor supra-individual dado a ele pelo processamento sociológico dogmático ou jurídico". ${ }^{50}$
\end{abstract}

O conceito ciência normativa não se refere a uma disciplina ou caracterização estabelecida naquele momento. Ele pode ser encontrado como tendo um papel central, como ocorre na análise de Hans Kelsen. ${ }^{51} \mathrm{O}$ próprio Kantorowicz não o explicou mais e não o desenvolveu em outros escritos. O conceito deve expressar o caráter normativo peculiar da dogmática jurídica: ao contrário da sociologia jurídica, ele não apenas relaciona fenômenos teoricamente a valores, mas também se autoavalia e é, portanto, prático. Apenas uma opinião pessoal do respectivo cientista

\footnotetext{
${ }^{46}$ Kantorowicz, Rechtswissenschaft und Soziologie, p. 121. Equivalente também id. Legal Science, p. 702.

47 Kantorowicz, Rechtswissenschaft und Soziologie, p. 127 s.

${ }^{48}$ Kantorowicz, Rechtswissenschaft und Soziologie, p. 132.

${ }^{49}$ Kantorowicz, Rechtswissenschaft und Soziologie, p. 97.

50 Kantorowicz, Rechtswissenschaft und Soziologie, p. 134.

${ }^{51}$ Hans Kelsen, Die Rechtswissenschaft als Norm- oder als Kulturwissenschaft (1916), in: Hans Kelsen, Werke, Matthias Jestaedt (Org.), Vol. 3, Tübingen 2010, p. 551. Por trás disso, está a distinção entre o método explicativo e o normativo, ver também do mesmo autor Hauptprobleme der Staatsrechtslehre entwickelt aus der Lehre vom Rechtssatze (1911), in: Hans Kelsen, Werke, Matthias Jestaedt (org.), Vol. 2, Tübingen 2008, p. 54 s.
} 
não deve ser vinculada a ela. Essa "ciência normativa" difere significativamente da ideia de Kelsen de uma ciência do direito como ciência normativa, que, segundo Kelsen, não se autoavalia. A ciência do direito de Kantorowicz como ciência normativa faz declarações sobre como as leis devem ser interpretadas e as lacunas preenchidas, com vistas aos objetivos que as leis seguem. ${ }^{52}$

Essas considerações classificadoras e ordenadoras de Kantorowicz podem ser vistas como uma adição sistemática às suas observações da história das ideias sobre os tipos de desenvolvimento no pensamento jurídico. Em seu ensaio sobre as Epochen der Rechtswissenschaft (Épocas da ciência jurídica), ele identifica direções "formalistas" e "finalistas" que não se seguem historicamente, mas que caracterizam certas épocas do desenvolvimento jurídico como elementos bastante relutantes. ${ }^{53} \mathrm{O}$ próprio Kantorowicz, com suas disposições sobre a ciência do direito como ciência normativa, claramente representa esse pensamento finalista.

Mais uma vez, as considerações de Kantorowicz mostram uma mudança entre finalidade e valor. A leitura levanta questões: a atribuição de um objetivo, segundo Kantorowicz, é o mesmo que uma avaliação? Se as relações de finalidade e meio são entendidas como relações causais, que conexão elas têm com uma visão avaliativa? Talvez as finalidades, para que possam ser entendidas e usadas, devam ser vistas como valores? Essas ambivalências devem ser investigadas.

\section{IV - Direito como dogma}

Kantorowicz define como conceito maior (Oberbegriff) do direito, como genus proximum, o conceito de regra. ${ }^{54}$ Isso corresponde ao costume da teoria jurídica da época. ${ }^{55}$ Por mais óbvia que a determinação possa parecer, é também um estreitamento notável. Por que regras - não argumentos, ideias, ações ou qualquer outra coisa? Mas esse estreitamento é acompanhado por uma expansão igualmente notável. Kantorowicz distingue três tipos de regras - começando com o ensaio Legal Science (Ciência Jurídica) de 1928: comandos, normas e dogmas. É uma distinção

\footnotetext{
52 Kantorowicz, Rechtswissenschaft und Soziologie, p. 137.

53 Hermann Kantorowicz, Die Epochen der Rechtswissenschaft (1914), in: id. Rechtshistorische Schriften, Karlsruhe 1970, p. 1.

54 Ver Kantorowicz, Begriff des Rechtes, p. 38.

55 Ver apenas Ernst Rudolf Bierling, Juristische Prinzipienlehre, Vol. 1, 1894 (Reimpressão Aalen 1979), p. 19.
} 
baseada no fundamento de validade. ${ }^{56}$ Enquanto os comandos se baseiam na autoridade, e os regulamentos em um dever de consciência, os dogmas vinculam "porque são consequências lógicas de outras regras, cuja validade já é reconhecida"57. A mudança talvez radical, que vem com essa diferenciação em comparação com a visão tradicional, é que o direito não se equipara simplesmente aos comandos, ou seja, às ordens autoritativas ou às normas, isto é, afirmações que são percebidas como obrigatórias. $O$ direito não é essencialmente um comando ou um preceito. $\mathrm{O}$ direito é, acima de tudo, dogma. Dogmas

"devem ser reconhecidos, independentemente de seu conteúdo ou origem, como parte de um sistema equilibrado, independente e, portanto, devem ser aceitos de forma acrítica ou dogmática. Comandos são coisas reais, normas [ou seja, prescrições] são valores, e dogmas, como uma terceira categoria, devem, consequentemente, ter significados objetivos". ${ }^{58}$

Kantorowicz toma, de maneira argumentativa, a natureza dogmática do direito a partir de uma delimitação dupla, em comparação com os comandos, por um lado, e os valores, por outro. A ciência jurídica pode lidar com a realização ou com o valor das regras. "Mas nem a realidade jurídica, nem o valor jurídico são o direito propriamente". ${ }^{59} \mathrm{Se}$ as regras jurídicas fossem comandos, elas teriam que estar sujeitas a mudanças na realidade. Mas não é assim: o direito não muda necessariamente se o comandante muda suas intenções e ideias. Se, por outro lado, as regras jurídicas tivessem o caráter de prescrições, não seria possível explicar por que os juristas nunca se restringiram a analisar as ideias de justiça e equidade, nem por que o direito injusto é frequentemente considerado válido.

Enquanto Kantorowicz, no artigo Legal Science, atribui as regras jurídicas exclusivamente aos dogmas, ele apresenta, em The Definition of Law (A definição do direito), a qualificação de maneira um pouco mais aberta, enfatizando que a distinção entre os três tipos de regras não deve ser entendida como uma atribuição exclusiva. A distinção fornece aspectos para a análise de regras. Uma regra não pode se enquadrar em um, dois ou nos três tipos de regra, pois então ela não tem mais vigência. Kantorowicz ilustra isso usando o exemplo dos Dez Mandamentos. Eles podem aplicar-se porque provêm da autoridade divina, porque são moralmente bons

\footnotetext{
${ }^{56}$ Kantorowicz, Begriff des Rechtes, p. 45.

57 Kantorowicz, Begriff des Rechtes, p. 46.

58 Kantorowicz, Rechtswissenschaft und Soziologie, p. 89.

59 Kantorowicz, Rechtswissenschaft und Soziologie, p. 90; um pouco mais detalhado em Kantorowicz, Begriff des Rechtes, p. 45-50.
} 
e porque representam "um todo coerente (ou pelo menos [...] um conjunto de normas que são transformadas em um sistema através da interpretação"). ${ }^{60}$

Obviamente, cada um desses três tipos de regras corresponde a uma área da ontologia kantorowicziana da realidade, valor e significado. Dogmas são estruturas. Essa tarefa pode não parecer particularmente original, especialmente porque naquela época, dentro do neokantismo e da fenomenologia, o terreno estava preparado para colocar sentido e significado no centro dos problemas das ciências humanas. Kantorowicz sabia muito bem o que fazer. ${ }^{61}$ Mas a abordagem de Kantorowicz tem duas peculiaridades que merecem ser enfatizadas. Primeiro: Kantorowicz usa o termo dogma com sua própria marca. Ele mesmo aponta para esse fato, observando de maneira casual e um tanto nebulosa que o conceito de dogma raramente é usado. ${ }^{62}$ Para Kantorowicz, um dogma não é simplesmente uma doutrina, pois corresponderia ao significado teológico e jurídico comum. O conceito de dogmática era um conceito familiar para a teologia e o direito na virada do século. Kantorowicz atribui ao conceito de dogma um significado mais estreito e semântico. Para ele, de acordo com o ensaio Staatsauffassungen (Concepções de Estado), "dogmático" é inicialmente um atributo daquelas ciências que lidam com significados e não com números. ${ }^{63}$ Isso está relacionado à avaliação acima mencionada de que o direito deve, da mesma maneira que os números, ser interpretado como significado. A visão de Kantorowicz revela traços de uma visão mais antiga do termo dogma, usado no Stoa para conhecimento

\footnotetext{
60 Kantorowicz, Begriff des Rechtes, p. 48.

61 Para o neokantismo, ver Kantorowicz, Rechtswissenschaft und Soziologie, para a fenomenologia, por um lado, Kantorowicz, Resenha de Reinach, p. 111 (para o significado desta resenha, ver Muscheler, Relativismus und Freirecht, p. 61), para outras referências da correspondência: Kantorowicz, como escreve Radbruch, encontra em Edmund Husserl seus pensamentos préconcebidos sobre "sentido" (Sinn) - que Husserl chama de "significado" (Bedeutung). (Carta de 21.7.1916, Konvolut Universitätsarchiv Freiburg, Caderno 164). Provavelmente eles estão se referindo às Logischen Untersuchungen de Husserl, 1900/1901, talvez também às Ideen zu einer reinen Phänomenologie und phänomenologischen Philosophie. Allgemeine Einführung in die reine Phänomenologie, 1913). Kantorowicz, no entanto, rejeitou a apresentação de um programa de essência, porque "em vez de pesquisar e projetar" leva à criação estéril (Carta a Radbruch de 16.8.1916, Konvolut Universitätsarchiv Freiburg, Caderno 165). Aprende-se muito em Husserl „sobre Teoria da Interpretação" (Carta a Radbruch de 16.8.1916, Konvolut Universitätsarchiv Freiburg, Caderno 165). Kantorowicz leu "uma apresentação muito boa da filosofia de Husserl" (Carta a Radbruch de 16.8.1916, Konvolut Universitätsarchiv Freiburg, Caderno 165), com a qual Joseph Geyser, Neue und alte Wege der Philosophie. Eine Erörterung der Grundlagen der Erkenntnis im Hinblick auf Edmund Husserls Versuch ihrer Neubegründung, Münster 1916, poderia ser entendida.

62 Kantorowicz, Begriff des Rechtes, p. 50.

${ }^{63}$ Kantorowicz, Staatsaufschauungen, p. 70. Para as muitas facetas do significado do conceito de dogma ou dogmático, ver Christian Bumke, Rechtsdogmatik. Eine Disziplin und ihre Arbeitsweise. Zugleich eine Studie über das rechtsdogmatische Arbeiten Friedrich Carl von Savignys, Tübingen 2017, p. 1, NR. 1, do ponto de vista filosófico M[artin]. Elze, Art. "Dogma", in: Joachim Ritter (Org.), Historisches Wörterbuch der Philosophie, Vol. 2: D-F, Darmstadt 1972, p. 275-277.
} 
intelectual e insensato, e de maneira muito semelhante em Christian Wolff para sentenças universais e não-factuais. ${ }^{64}$ Não está claro em seus escritos e materiais de carta se Kantorowicz estava familiarizado com tais leituras.

Por outro lado, a "teoria dos dogmas" de Kantorowicz é original em termos da lógica especial dos dogmas que ele associa a ela. Isso leva a uma compreensão do conceito de dogmática que não é congruente com a compreensão contemporânea. Dogmas formam um "conjunto de regras [...] cuja coesão lógica é sua própria garantia". ${ }^{65}$ Kantorowicz não pode afirmar exatamente que tipo de lógica é essa. De qualquer forma, não deve ser uma silogística clássica. ${ }^{66}$ As regras de um sistema desse tipo devem ser comparadas e concluídas, elas são de apoio mútuo:

\begin{abstract}
"O processo consiste em uma reciprocidade sem fim de alinhamento, conclusão e eliminação; o objetivo é criar um sistema completo. Seria uma conclusão circular basear a validade da regra $A$ na da regra $B$ e a última sobre a validade da regra $A$; o processo, em verdade, consiste em alinhar a regra $B$ com a regra $A$ e vice-versa - com o resultado de que $A$ se transforma em A (1) e B em B (1), e assim por diante ad infinitum". 67
\end{abstract}

Essa é uma passagem fascinante. Kantorowicz imagina uma lógica proceduralizada, uma lógica que não garante resultados confiáveis com conclusões estáticas, mas que permite que as declarações sejam coordenadas entre si em constante movimento. As fórmulas dogmáticas não são, portanto, certas ou erradas, mas apenas mais ou menos apropriadas. ${ }^{68} \mathrm{~A}$ integralidade das declarações deve ser uma meta, mas aparentemente inatingível. O sistema é autossustentável, por assim dizer, não tem um ponto arquimediano. Como Kantorowicz enfatiza, não existe uma "regra básica" que possa provar a validade de tais sentenças dogmáticas. ${ }^{69}$ Kantorowicz teria gostado de ver, décadas depois, a teoria filosófica da argumentação ter se distanciado da lógica clássica. ${ }^{70}$ Suas observações superficiais também mostram paralelos interessantes com abordagens mais recentes em epistemologia e metaética, que se concentram na ideia de coerência. ${ }^{71}$ Vários conceitos coerentes

\footnotetext{
64 Sobre isso Elze, Art. „Dogma“.

65 Kantorowicz, Begriff des Rechtes, p. 46. Itálico do autor.

66 Kantorowicz, Begriff des Rechtes, p. 46.

67 Kantorowicz, Begriff des Rechtes, p. 46. Itálico no original.

68 Kantorowicz, Staatsauffassungen, p. 70; no mesmo sentido, Kantorowicz, Tat und Schuld, p. 33 s.

69 Kantorowicz, Begriff des Rechtes, p. 46.

70 Ver Stephen E. Toulmin, The Uses of Argument, 2a. ed. 2003 (Reimpressão Cambridge entre outros 2008); Harald Wohlrapp, Der Begriff des Arguments. Über die Beziehungen zwischen Wissen, Forschen, Glauben, Subjektivität und Vernunft, Würzburg, 2008.

71 Sobre a moral ver, não por último, Dworkin, Justice for Hedgehogs, p. 113 s.; o equilíbrio reflexivo em John Rawls - Kantorowicz: “ajuste recíproco” (wechselseitige Anpassung) - também pode ser pensado.
} 
também foram desenvolvidos para a ciência do direito. ${ }^{72}$ Coerência é mais do que apenas consistência no sentido de ausência de contradição. Além, por assim dizer, da função negativa, as declarações podem promover algo positivo, no sentido de se apoiarem reciprocamente. Qualquer tipo de fundamento do sistema de declarações coerentes sobre um fundamento seguro não está conectado a ele, e é por isso que essas posições são caracterizadas como anti-ou non-foundationalism. O coerentismo evita o regresso infinito ou o aborto do regresso, dando ao conhecimento justificado uma estrutura semelhante a uma rede. Ele está, obviamente, sujeito à objeção de permitir sistemas de conhecimento concorrentes, mas igualmente justificados, pois coerente. A posição coerentista sugerida por Kantorowicz não se refere à realidade ou aos valores - nem à epistemologia nem à metaética -, mas ao dogma como significado e, portanto, diretamente à ciência do direito.

\section{Direito livre e interpretação jurídica}

A literatura considera, em parte, que o trabalho tardio de Kantorowicz se afastou do desenvolvido em seu início e se aproximou de uma visão tradicional do dogma jurídico. ${ }^{73}$ Essa avaliação pode estar correta, mas negligencia um ponto importante. Se bem entendi, os dogmas do trabalho tardio de Kantorowicz assumem a posição que ocupava o direito livre nos primeiros trabalhos. Porque apenas o desvio, por meio da tese do direito como dogma e significado (die Recht-als-Dogma-als-SinnThese), permite a Kantorowicz atribuir ao direito livre um local adequado. Essa conexão agora deve ser examinada em mais detalhes.

\section{Direito livre como dogmática?}

(John Rawls, Eine Theorie der Gerechtigkeit, Frankfurt am Main 1979, p. 38; Kantorowicz, Tat und Schuld, p. 34). Para uma ampla literatura, apenas Geoffrey Sayre-McCord, Coherentist Epistemology and Moral Theory, in: Walter Sinnott-Armstrong/Mark Timmons (Orgs. ), Moral Knowledge?, New York, NY 1996, p. 137; Sem de Maagt, Reflective Equilibrium and Moral Objectivity, Inquiry 60 (2016), p. 443. 72 Em geral: Benjamin C. Zipursky, Legal Coherentism, S. M. U. L. Rev. 50 (1997), p. 1679; Susanne Bracker, Kohärenz und juristische Interpretation, Baden-Baden 2000; também deve ser mencionado Nigel E. Simmonds, Law as a Moral Idea, 2007 (Reimpressão Oxford 2010), p. 164 s.; ver Andreas Funke, Die Konstellation der Rechtssicherheit, in: Jan C. Schuhr (Org.), Rechtssicherheit durch Rechtswissenschaft, Tübingen 2014, p. 49 (64).

${ }^{73}$ Thomas Raiser, Hermann Ulrich Kantorowicz, in: Marcus Lutter/Ernst C. Stiefel/Michael H. Hoeflich (Org.), Der Einfluß deutscher Emigranten auf die Rechtsentwicklung in den USA und in Deutschland, Tübingen 1993, p. 365, S. 376; também, cuidadosamente, Ino Augsberg, Hermann Kantorowicz und die Freiheit des Rechts, p. 224. 
Kantorowicz sempre teve dificuldades em afirmar exatamente o que é realmente o direito livre. A literatura secundária também luta com o conceito. ${ }^{74} \mathrm{O}$ termo "infeliz"75 inclui coisas muito diferentes, como projetos de leis e as normas de caso concreto que um juiz estabelece para resolver uma questão jurídica difícil. Kantorowicz inicialmente colocou o direito livre em uma estreita conexão com o direito natural ${ }^{76}$ e o descreveu como uma fonte do direito. ${ }^{77} \mathrm{O}$ início tempestuoso foi seguido por tentativas de colocar ordem. Em seu ensaio sobre a Legal Science, Kantorowicz desenvolveu uma sistematização e apontou seis formas diferentes de direito livre.

Como mencionado, vejo o conceito de dogma como a chave para entender o direito livre, mesmo que com essa interpretação o conceito de direito livre possa ter que ceder um pouco, ou seja, nem todos os aspectos relacionados por Kantorowicz podem ser inseridos completamente na interpretação sem contradição. Devemos, portanto, recordar as dificuldades especiais na interpretação do pensamento de Kantorowicz, mencionadas no início deste artigo, e as liberdades associadas. $\mathrm{O}$ conceito de dogma é importante porque dogmas e direito livre são funcionalmente equivalentes. A seguinte consideração é crucial para essa visão: o direito livre deve mostrar que a ciência do direito não pode tratar o direito apenas como um comando, porque, como um comando, ele está necessariamente incompleto. Para recordar esta famosa frase da "luta pela ciência do direito", a lei contém "não menos lacunas que palavras"78. Foi precisamente com essa necessidade de preencher as lacunas que Kantorowicz, mais tarde, justificou a interpretação de que a ciência do direito tratava o direito como uma coleção de dogmas ${ }^{79}$ :

\footnotetext{
"Mas ainda a dogmática, o núcleo da ciência do direito, certamente nunca tratou o direito como um conjunto de comandos. Se assim fosse, ela não estaria tão ansiosa para preencher as lacunas do direito, estabelecendo regras para a decisão de casos imprevistos e projetando construções de longo alcance para dominar o imprevisto e o imprevisível. Ela não deveria ter visto sua tarefa principal de integrar as regras em um sistema, mas deveria

74 Ver, por exemplo, os esforços muito diferentes em Joachim Schmidt, Das „Prinzipielle" in der FreirechtsBewegung. Eine Studie zum Frei-Recht, seiner Methode und seiner Quelle, Bonn 1968, p. 47 s.; Dietmar Moench, Die methodologischen Bestrebungen der Freirechtsbewegung auf dem Wege zur Methodenlehre der Gegenwart, Frankfurt am Main 1971, S. 14 ff., $87 \mathrm{ff}$.

${ }^{75}$ Arthur Kaufmann, Einführung, in: Ernst Fuchs, Gerechtigkeitswissenschaft, Albert S. Foulkes/Arthur Kaufmann (Org.), Karlsruhe 1965, p. 1 (1); Raiser, Hermann Ulrich Kantorowicz, p. 372.

${ }^{76}$ Kantorowicz, Der Kampf um die Rechtswissenschaft, p. 15; sobre isso Muscheler, Relativismus und Freirecht, p. 78 (N.R., 297).

77 Kantorowicz, Der Kampf um die Rechtswissenschaft, p. 21.

78 Kantorowicz, Der Kampf um die Rechtswissenschaft, p. 18.

${ }^{79}$ Kantorowicz, Der Kampf um die Rechtswissenschaft, p. 49.
} 
tê-las visto (em vão) de tentar atribuir as regras às intenções transitórias e subjetivas dos legisladores e suas visões nunca abrangentes e raramente míopes". ${ }^{80}$

Este é um ponto-chave, pois mostra a estreita conexão entre direito livre e dogmática. A rejeição da natureza dominante do direito leva ao direito livre, bem como à tese do direito como dogma e significado. Na última parte das minhas observações (em IV e V), gostaria de explicar um pouco mais precisamente o que isso significa. Antes disso, no entanto, existem algumas inconsistências que não considero possíveis resolver no momento. Elas estão relacionadas à maneira pela qual Kantorowicz desenvolve o conceito de dogma. Como mostrado, isso é feito, por um lado, na delimitação de comandos autoritativos e, por outro, na prescrição de moralidade ou justiça. Kantorowicz não é capaz de distinguir entre os dois. $\mathrm{O}$ direito como dogma é autoritário em alguns aspectos em relação à jurisprudência (em II), e está conectado à justiça (em III).

\section{Dogma e autoridade}

A validade dos dogmas não deve depender de uma regra externa ou mesmo de um comando. Kantorowicz vê completa independência aqui. ${ }^{81}$ Mas Kantorowicz não se separa completamente da ideia de que existe uma conexão entre direito e autoridade. Isso já é mostrado pelo exemplo dos Dez Mandamentos. Mesmo que eles formem um sistema dogmaticamente, essa validade dogmática deve ter alguma conexão com o decreto autoritativo. Caso contrário, os cristãos jamais pensariam em estabelecer o sistema de mandamentos. Outros sistemas também seriam concebíveis. O sistema de Dez Mandamentos é formado apenas porque Deus o deu a Moisés. Outro aspecto também mostra que os dogmas não podem ser pensados inteiramente sem autoridade, pelo menos na ciência do direito. Porque os objetivos devem ser autoritativos. ${ }^{82}$ Mas eles são autoritativos apenas em um certo sentido. Porque os objetivos individualmente demonstráveis dos atores legislativos não devem ser de importância decisiva. A consideração do objetivo apenas fornece a estrutura formal para as operações dogmáticas. A construção jurídica não pode dispor

\footnotetext{
80 Kantorowicz, Begriff des Rechtes, p. 49 s.

${ }^{81}$ Kantorowicz, Begriff des Rechtes, p. 46. Claramente nesse sentido também Marietta Auer, Der Kampf um die Wissenschaftlichkeit der Rechtswissenschaft, ZEuP 2015, p. 773 (787).

82 Ver acima C III.
} 
livremente dos objetivos ou determiná-los arbitrariamente. Os objetivos devem ser construídos, projetados, com referência aos dados e interpretações transmitidas. Novamente, precisamos lembrar a mudança de Kantorowicz entre objetivo e valor: na abordagem dogmática, eles se aproximam a ponto de serem indistinguíveis, porque a abstração de propósitos mostra o que é valioso.

\section{O papel da justiça na dogmática}

Dificuldades semelhantes surgem quando se trata de justiça. Kantorowicz não afirma claramente qual o papel da justiça no direito e na ciência do direito. Há observações que indicam uma exclusão; alguns já foram discutidos. Segundo Kantorowicz, a interpretação dogmática do direito deve ignorar a questão ética ou política da justiça ou injustiça do direito, porque é apenas uma questão da unidade interna do sistema. ${ }^{83}$ Isso contrasta com afirmações, segundo as quais, a consideração dogmática inclui a justiça. Kantorowicz ressalta que, no caso de várias interpretações possíveis ou acréscimos a uma lei, a dogmática sempre recorreu aos princípios - "preceitos" - de justiça e equidade. ${ }^{84}$ Mais tarde, com considerações semelhantes, Ronald Dworkin argumentou contra o positivismo de H. L. A. Hart que as justificativas jurídicas frequentemente se referem não apenas a regras, mas também a princípios morais. ${ }^{85} \mathrm{~A}$ distinção não coincide com a de Kantorowicz entre comando e preceito ou entre comando e dogma. Dworkin vê a distinção como "lógica", no sentido de que os dois tipos de padrões são aplicados de maneira diferente. Os princípios apenas fornecem argumentos que apontam para uma determinada direção sem, como as regras, exigir uma certa decisão. ${ }^{86}$ Mas o argumento de Dworkin de que as regras não descrevem exaustivamente o que os juristas fazem é semelhante ao raciocínio de Kantorowicz de que o direito não pode ser visto apenas como um comando.

Mas como explicar a contradição de que a justiça deveria "ser considerada" uma vez, mas não declarada novamente, ou talvez até remediada? É útil supor que Kantorowicz distingue justiça formal e substancial. De qualquer forma, certos

\footnotetext{
${ }^{83}$ Kantorowicz, Rechtswissenschaft und Soziologie, p. 90.

${ }^{84}$ Kantorowicz, Begriff des Rechtes, p. 50. Por outro lado, a História do Direito não deve pesquisar a correta, mas a interpretação real de uma norma. (p. 51).

85 Dworkin, Taking Rights Seriously, p. 46 s.

${ }^{86}$ Dworkin, Taking Rights Seriously, p. 26.
} 
elementos teóricos podem ser explicados dessa maneira. Uma conexão entre significado e valor surge, entre outras coisas, do fato de que a unidade interna do sistema é em si um valor de justiça, mais precisamente de igualdade. Kantorowicz sugere isso casualmente. Ele vê a sistematização de regras como uma racionalização, e isso significa "libertar as regras de contradições e lacunas, inserindo-as em um sistema coerente e independente, para que possamos tratar a mesma coisa, porque é isso que é a essência da justiça"87. A igualdade, nesse sentido, entendida como justiça formal, moldou a ideia de um sistema completo de regras desde o início. Mas isso não se dá inteiramente sem tensão. A validade das regras baseadas no sistema deve ser, aparentemente, independente de considerações substanciais de justiça. Esta é a única maneira de explicar que, segundo Kantorowicz, a validade dogmática de uma norma não pode ser contestada com vistas a sua injustiça. Uma regra injusta também pode fazer parte de um sistema coerente. Só há espaço para considerações substantivas de justiça no plano da aplicação das regras. É aqui que entra a justiça. Segundo Kantorowicz, as lacunas do direito são preenchidas usando o direito livre, que também é determinado por considerações jurídico-filosóficas. ${ }^{88} \mathrm{Em}$ seu manual de direito penal, Kantorowicz mostra o que isso significa. O requisito de coerência está vinculado a um procedimento de controle de resultados orientado à justiça: "Somente se os resultados forem justos, módicos, fáceis de usar e puderem ser executados com segurança, é possível confiar no sistema no qual eles fluem" 89 . Esse controle de resultado é praticado extensivamente por Kantorowicz na descrição. Ele vê em um consenso sobre a ideia de culpa o requisito dominante para a justiça no direito penal, a justificativa especial para sua abordagem coerente.

\section{Direito livre como direito}

Em termos práticos, o direito livre é em grande parte a massa de sentenças que são apresentadas como interpretações de leis e não simplesmente reproduzem o texto da lei.90 É ao mesmo tempo irritante e estimulante pensar que Kantorowicz

\footnotetext{
87 Kantorowicz, Begriff des Rechtes, p. 98.

88 Kantorowicz, Begriff des Rechtes, p. 98. Nesse contexto, Kantorowicz nomeia princípios como segurança jurídica, estabilidade, igualdade; no entanto, não está claro se as considerações jurídicofilosóficas mencionadas são assim determinadas.

89 Kantorowicz, Tat und Schuld, p. 33 s.

90 Ver Kantorowicz, Rechtswissenschaft und Soziologie, p. 94; Em particular, a categoria „begehrten gesetzten Rechts" (direito legal cobiçado), grupo 2, é relevante. No original em inglês: "A part of the
} 
descreve o direito livre como um direito. A ciência jurídica é, ela própria, na antiga terminologia, uma fonte do direito. Kantorowicz diz isso expressamente em seus primeiros trabalhos. ${ }^{91}$ Isso é irritante, porque sentenças dogmáticas ou de direito livre não são um direito formal. Mas a ciência não é uma fonte do direito porque cria direito formal, mas porque desenvolve interpretações. Além disso, nada mais se aplica aos tribunais, aos quais voltaremos em breve. Kantorowicz pode, portanto, também ser entendido de tal maneira que ele não (apenas) veja o direito como objeto do conhecimento jurídico, que a ciência como sujeito enfrentaria. Como demonstrou sua rejeição ao argumento circular neokantiano, o direito também não é criado no sentido neokantiano de uma constituição transcendental de objeto. Portanto, é compreensível a crítica de Kantorowicz ao pensamento jurídico de Friedrich Carl von Savigny: ele acusa Savigny de "intelectualismo", "que fez dos juristas uma mera ferramenta de reconhecimento, replicação e operação lógica, que rejeita todos os valores e é desprovida de qualquer poder criativo"92. O oposto é o caso e, como esse oposto pode ser descrito, é o que gostaria de propor Kantorowicz. Direito livre é direito, porque e na medida em que se enquadra na lógica do significado jurídico.

Nesse contexto, Arthur Kaufmann está, definitivamente, correto ao interpretar o conceito "direito" do artigo 20, frase 3 da Lei Fundamental alemã como um direito no espírito do direito livre. ${ }^{93}$ Mas não devemos perder a linha que seria associada a essa interpretação. Na falta de formalidade, "direito", na acepção do artigo 20, frase 3 da Lei Fundamental, não é "lei" na acepção desta prescrição. Esse "direito" não pode, portanto, ser entendido de tal maneira que pertencesse a um corpo fixo do sistema jurídico, semelhante à lei. Em vez disso, é projetado, testado, aplicado, seguido e praticado por atores jurídicos usando processos de produção de significado.

No entanto, permanece a questão de por que, segundo Kantorowicz, as regras e interpretações do direito livre desejam tornar-se um direito formal. ${ }^{94}$ A existência do

\footnotetext{
interpretive law, i. e., interpretations which feign to be mere declarations of the statute, but, as is nearly always the case, cannot be strictly deduced from it and in fact are nothing but the statute as the interpreter desires it to be". Na tradução alemã interpretive law é feita como Auslegungsregeln. No entanto, não está correta, pois as interpretações são elas mesmas. Melhor, portanto, Raiser, Hermann Ulrich Kantorowicz, p. 377, que traduz interpretive law como Gesetzesinterpretationen.

91 Kantorowicz, Der Kampf um die Rechtswissenschaft, p. 21.

92 Hermann Kantorowicz, Was ist uns Savigny (1911), in: id., Rechtshistorische Schriften, p. 397.

${ }^{93}$ Kaufmann, Einführung, in: Ernst Fuchs, Gerechtigkeitswissenschaft, p. 17, referindo-se à decisão do Tribunal Constitucional Federal Alemão: BVerfGE 34, 269 (286 s.) - Soraya. Consta do art. 20, frase 3 da Lei Fundamental alemã: „O poder legislativo está vinculado à ordem constitucional; os poderes executivo e judiciário obedecem à lei e ao direito.".

${ }^{94}$ Kantorowicz, Rechtswissenschaft und Soziologie, p. 94.
} 
direito livre seria uma condição deficiente a ser superada; o direito livre trabalharia sempre pela sua própria abolição. Uma explicação para a aceitação desse "desejo" poderia ser que Kantorowicz é mais fortemente influenciado pela ideia de formalidade do que indica a distância desse termo do conceito de direito livre. É claro que Kantorowicz não está livre dos padrões de pensamento de seu tempo. ${ }^{95}$ Seu pensamento foi baseado, em particular, na ideia de fonte do direito. O direito livre teria sido infectado pela ideia de formalidade. Mas outra explicação para o fato seria que Kantorowicz desejava que o direito livre se tornasse direito formal. O "desejo" cumpre um importante requisito de demarcação. Por falta de formalidade, em particular, o direito livre tende a ser aberto a outras formas de natureza normativa. Kantorowicz usa o critério do desejo para distinguir "direito livre como direito" de "costume", ou seja, de normas e convenções sociais que não são direito e - talvez apenas temporariamente - não desejam se transformar em direito. ${ }^{96}$ Por trás disso, está a interpretação de Kantorowicz da origem do direito como uma racionalização do costume. ${ }^{97} \mathrm{O}$ ensino jurídico está intimamente ligado à normatividade social, mas o direito pode e deve ser diferenciado dela. Kantorowicz quer tornar isso possível pelo fato de que apenas essas regras podem ser entendidas como regras jurídicas que têm o "desejo" mencionado. O problema agora surge de maneira comparável para as teorias jurídicas que desejam basear o direito não apenas em fatos sociais (sources thesis $^{98}$, mas adquirem outras características. A teoria de Dworkin, por exemplo, está sujeita à objeção de que, devido à falta de demarcação da moralidade, ela não faz justiça à autonomia do direito. Kantorowicz vê esse problema em sua tese do direito como dogma e significado e tenta manter o direito como sistema autônomo ao aceitar esse "desejo".

O deslumbrante conceito de direito livre é enganoso, entre outras coisas, porque está associado a interpretações arbitrárias do direito. No entanto, como ficou claro, elas são, no máximo, livres, na medida em que não são autoritativas. Até certo ponto, o direito livre expressa uma obrigação. Porque todas as declarações que não

\footnotetext{
95 Mais tarde, ele defendeu que o dualismo do direito baseado na lei e o consuetudinário fosse substituído por um pluralismo abrangente de fontes jurídicas. Kantorowicz, Tat und Schuld, p. 29. Também Klaus Riebschläger, Die Freirechtsbewegung. Zur Entwicklung einer soziologischen Rechtsschule, Berlin 1968, p. 110, observa que a questão das fontes do direito "hoje" (1968) recebe menos atenção do que Kantorowicz poderia imaginar.

96 Ver Kantorowicz, Begriff des Rechtes, p. 85 s.

97 Kantorowicz, Begriff des Rechtes, p. 47, 75 s.

98 Joseph Raz, Ethics in the Public Domain. Essays in the Morality of Law and Politics, 1994 (Reimpressão Oxford New York 2001), p. 230 s.
} 
atendem aos critérios dos dogmas não são direito, não são direito livre. Quem deseja se envolver com a ciência do direito ou com a prática jurídica, deve usar a linguagem jurídica técnica. Isso é tudo, menos direito livre. Kantorowicz exemplifica isso em seu manual de direito penal, que ele identifica no prefácio como um "exemplo de métodos de direito livre". Como ele, imediatamente, acrescenta, isso significa apenas que o manual é "uma investigação dogmática e conceitual". 99 O processo de racionalização do direito, que Kantorowicz diagnostica no desenvolvimento social, é expresso no próprio direito por meio de requisitos para a racionalidade das declarações. Entender o direito livre como regra significa que as determinações jurídicas devem ter certas características formais. Deve ser possível generalizar as determinações em seus fundamentos. Aspectos relacionados apenas a um caso individual não podem ser transformados em regras; portanto, eles não podem ser alimentados na esfera dos significados jurídicos. A generalização dos fundamentos nada mais é do que fundamentação racional. ${ }^{100}$ Deste ponto de vista, o direito livre cobre o espaço dos fundamentos do direito. ${ }^{101}$

Portanto, não há diferenças entre as operações dogmáticas da ciência do direito e dos tribunais. Ambos trabalham construtivamente com dogmas. Em uma troca de cartas com Radbruch, sobre a questão de se os juízes criam direito, Kantorowicz atribui grande importância à distinção entre o julgamento judicial e os fundamentos que sustentam o julgamento. Ele é cético sobre o termo "direito do juiz"; o julgamento nunca poderia ser uma fonte do direito. No entanto, o raciocínio da decisão pode conter regras jurídicas válidas. Esse direito "ele [o juiz, A.F.] não o gerou como juiz, mas de maneira científica por causa da atividade geral. [...] Que o direito científico não 'tem validade' é puramente verdade, [...] mas a validade não é uma característica conceitual do direito". ${ }^{102}$ Isso mostra claramente a necessidade de se

\footnotetext{
${ }^{99}$ Kantorowicz, Tat und Schuld, p. VI, VII. Há também a bela argumentação, de que o objetivo é "a livre interpretação da lei, que deseja espiritualizar sua letra, destacando seu objetivo".

100 Ulfrid Neumann, Juristische Argumentationslehre, Darmstadt 1986, p. 104; Aleksander Peczenik, Grundlagen der juristischen Argumentation, Wien 1983, p. 170 s.; Delf Buchwald, Der Begriff der rationalen juristischen Begründung. Zur Theorie der juridischen Vernunft, Baden-Baden 1990, p. 254 s. ${ }^{101} \mathrm{~A}$ imagem do espaço dos fundamentos do direito provavelmente remonta a Wilfrid Sellars. Tornouse um símbolo de razoabilidade, que está faltando no reino da natureza, conforme, talvez, Robert Brandom, Expressive Vernunft. Begründung, Repräsentation und diskursive Festlegung, Frankfurt am Main 2000, p. 37.

102 Carta a Radbruch de 31 de outubro de 1912, Konvolut Universitätsarchiv Freiburg, Caderno 140. Resumidamente também da carta de 26 de outubro de 1992: "As regras contêm apenas os motivos [os fundamentos do julgamento são entendidos aqui como a parte separada do julgamento, como Rubrum, Tatbestand und Tenor - observação do autor] que não participam da força jurídica, exceto onde se tornam direito consuetudinário". (Konvolut Universitätsarchiv Freiburg, Caderno 138).
} 
identificar regras em virtude de sua universalização como parte do sistema dogmático de significado. A produção jurídica "científica", ou melhor, dogmática, é uma questão para os juízes e também para a ciência institucional.

\section{Pluralismo razoável de interpretações do direito}

Isso nos leva ao último ponto. Por definição, controvérsias em dogmática não podem ser resolvidas de maneira autoritativa. ${ }^{103}$ Marietta Auer interpretou, por isso, a teoria de Kantorowicz como "pluralismo jurídico interpretativo". ${ }^{104}$ Essa interpretação está totalmente de acordo com a linha que Karlheinz Muscheler havia traçado anteriormente. Ao contrário de Auer, no entanto, Muscheler faz uma forte crítica a Kantorowicz: Kantorowicz perde a peculiaridade teórica da atividade de interpretação jurídica, se não também sua realidade. Muscheler acredita que as interpretações sempre afirmam que o significado correto de uma norma foi alcançado. ${ }^{105} \mathrm{~A}$ interpretação jurídica sempre visa o significado "de algo (pelo menos sua reivindicação) de acordo com o dado e, portanto, deve ser cumprido ou não".

Aqui, Muscheler, por mais meritório que seja seu trabalho, não leva sistematicamente seu autor a sério. Muscheler argumenta exatamente como aqueles que sempre foram criticados por Kantorowicz. Ele reproduz apenas a visão do direito e da ciência do direito, contra a qual Kantorowicz opõe um argumento substantivo. Kantorowicz rejeita a ideia de que a ciência do direito se destina ao "conhecimento do que é conhecido"; ela não pode negar reivindicações em todos os casos em que a lei não as concede. ${ }^{106}$ Se houver uma lacuna, ela deve ser fechada pelo "direito livre".

\footnotetext{
103 De forma concisa, Auer, Der Kampf um die Wissenschaftlichkeit der Rechtswissenschaft, p. 787. Com um tom polêmico sobre a diversidade de interpretações Kantorowicz, Der Kampf um die Rechtswissenschaft, p. 25.

${ }^{104}$ Auer, Der Kampf um die Wissenschaftlichkeit der Rechtswissenschaft, p. 788. Ao mesmo tempo, ela identificou uma influência dos conceitos jurídicos judaicos. De maneira crítica a isso, Augsberg, Hermann Kantorowicz und die Freiheit des Rechts, p. 229 s.

105 Muscheler, Relativismus und Freirecht, p. 65.

106 Ver Kantorowicz, Der Kampf um die Rechtswissenschaft, p. 21. A frase "o reconhecimento do reconhecível” („Erkennen des Erkannten“), que ainda é usada na hermenêutica, vem do entendimento do filólogo August Boeeckh. Ver August Boeckh, Encyklopädie und Methodologie der Philologischen Wissenschaften, Leipzig 1886, p. 10). É digno de nota que Gustav Radbruch adota essa fórmula ainda mais claramente na polêmica "Ciência do Direito como Criação do Direito", que apareceu quase ao mesmo tempo, e que Kantorowicz a rejeita, mas de um modo um pouco mais pronunciado no contexto da teoria da interpretação ou da hermenêutica teológica ou filológica. (Gustav Radbruch, Rechtswissenschaft als Rechtsschöpfung (1906), in: Gustav Radbruch, Gesamtausgabe, Vol. 1, Arthur Kaufmann (Org.) , Heidelberg 1987, p. 409. Para a classificação hermenêutica deste ensaio, consulte Andreas Funke, Abschied von der Positivismus/Nicht-Positivismus-Schablone?, in: Martin Borowski (Org.), Modern German Nonpositivism, i. E.
} 
Gustav Radbruch, com quem Kantorowicz estava em estreito contato na época, formulou, no mesmo ano, esse argumento ainda mais claramente, como uma proibição de recusar o direito: ${ }^{107}$ com relação a novos casos, a lei era necessariamente incompleta; A rejeição de reivindicações devido a essa incompletude viola o direito de obter direitos. Muscheler, por outro lado, reintroduz o direito como "dado".

O argumento de Kantorowicz contra isso não se esgota na suposição de que as interpretações jurídicas são completamente equivalentes, como é o caso de acordo com a posição do relativismo de valor no caso dos últimos valores. Sem tirar expressamente essa conclusão, Kantorowicz prova que os diferentes resultados no trabalho de interpretação podem fazer sentido, apesar de sua diversidade. É razoável discutir sobre interpretações. O pluralismo da dogmática é um pluralismo razoável. Essa conclusão corresponde, no campo da dogmática, às suposições feitas no campo dos valores ao relativismo de valor, que por sua vez expressa as condições sob as quais é razoável argumentar sobre valores. ${ }^{108}$ A diversidade de interpretações não é uma mera justaposição ou mesmo uma justaposição agonal de interpretações. Kantorowicz mostra isso com seu conceito de direito livre. Podemos pensar em Dworkin uma última vez, que coloca a questão da possibilidade de desacordo sobre conceitos jurídicos no centro de sua teoria hermenêutica. ${ }^{109}$ Ao contrário do que Muscheler pensa, a disputa pela interpretação correta não diz respeito a nada que seja dado. Mesmo os objetivos que orientam a construção dogmática não são totalmente independentes dessa construção. A natureza de uma interpretação encontra-se, precisamente, na correção de uma certa interpretação, e não na existência de um comando determinado ou em como pode ser sentido um valor na consciência. É aqui que se encontra a lógica de Kantorowicz do sistema coerente, que só é sugerida e ofuscada na recepção de seu trabalho pelos atraentes topos do direito livre. Em conclusão, dentro deste sistema, a correção só pode ser processada. Mas isso não é um pouco.

Recebido em 20/02/2020 Aprovado em 20/04/2020

\footnotetext{
107 Radbruch, Rechtswissenschaft als Rechtsschöpfung, p. 409, 412.

${ }^{108} \mathrm{E}$ merece ser afirmado que Kantorowicz, em sua avaliação negativa de Savigny - "Tudo isso está incorreto" - rebateu as críticas de Savigny ao direito natural de que "um sistema de princípios jurídicos mais gerais correspondentes à natureza humana permanece pelo menos concebível, assim como o bom senso e as condições comuns de existência não são negados por ninguém". Kantorowicz, Savigny. In. Id. Rechtshistorische Schriften, p. 401.

109 Dworkin, Law's Empire, p. $3 \mathrm{~s}$.
} 
Received in 20/02/2020

Approved in 20/04/2020 